[Chem. Pharm. Bull.

$\left[\begin{array}{ll}\text { 35( } 2 \text { ) } 808-813 \text { (1987) }\end{array}\right]$

\title{
Macromolecular Complexes of Drugs. I. Doxorubicin-Heparin Complex
}

\author{
Toshinobu Aoyama, ${ }^{*, a}$ Masayoshi Horioka ${ }^{a}$ and Shingo Nagamitsu ${ }^{b}$ \\ Hospital Pharmacy, Kyushu University Hospital a and Department of Surgery I, \\ Faculty of Medicine, Kyushu University, ${ }^{b}$ Maidashi 3-1-1, \\ Higashi-ku, Fukuoka 812, Japan
}

(Received August 19, 1986)

\begin{abstract}
As a part of our studies to develop anticancer agents with prolonged action and reduced side effects, we examined the macromolecular complex of doxorubicin and heparin. Formation of a complex of doxorubicin and heparin was confirmed by HIAC, infrared, ultraviolet, differential scanning calorimetry, energy micro analysis X-ray and high performance liquid chromatography analysis. If the molecular weight of heparin is assumed to be 9800 , one molecule of heparin binds 16 molecules of doxorubicin.
\end{abstract}

Keywords -complex; heparin; doxorubicin; anticancer drug; macromolecular complex; particle count; energy dispersing X-ray

Generally, anticancer drugs do not exhibit prolonged action at the tumor site because of their short retention time in the blood and tissues due to their low-molecular charactes. Side effects, however, can be severe if high drug concentrations are sustained in the blood for a long time. In an effort to develop safer and more effective drugs, the use of anticancer agents bound with macromolecular compounds has been suggested, such as methotrexate-poly(1lysine) complex, ${ }^{1)}$ polystyrene maleic acid-neocarzinostatin complex, ${ }^{2)}$ polyglycolic acid-5fluorouracil complex, ${ }^{3)}$ and mitomycin $\mathrm{C}$-dextran conjugate. ${ }^{4)}$

While studying macromolecular complexes of anticancer compounds and biological components in order to find anticancer substances which can be administered locally, we have noted reports that heparin form complexes with various drugs having an $\mathrm{NH}_{2}$ moiety, such as streptomycin, ${ }^{5,6)}$ polymixin $M,{ }^{5)}$ monomycin, kanamycin and neomycin. ${ }^{6)}$ We have investigated the ability of heparin to form complexes with some anticancer drugs and report here the results on the complex of doxorubicin and heparin (Chart 1).

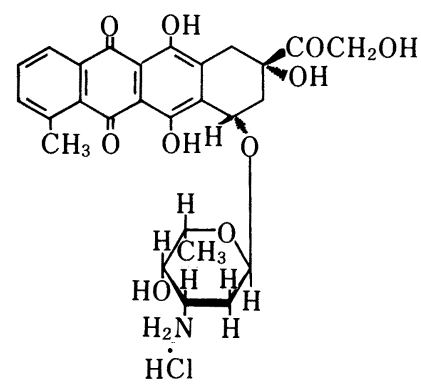

doxorubicin hydrochloride

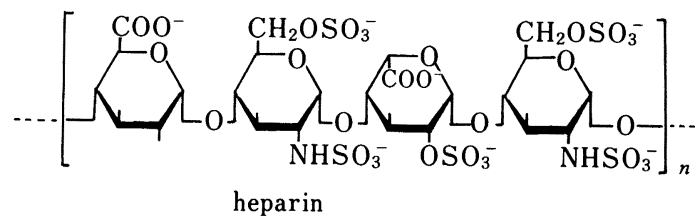

heparin 


\section{Experimental}

Materials_-Doxorubicin hydrochloride (Dox-HCl) was a gift from Kyowa Hakko Co., Ltd. (Tokyo, Japan). Heparin sodium (Hep-Na), a reagent, was obtained from Tokyo Kasei Kogyo Co., Ltd. (Tokyo, Japan). Novoheparin injection was obtained from Kodama Co., Ltd. (Tokyo, Japan). An 8.4\% sodium bicarbonate $\left(\mathrm{NaHCO}_{3}\right)$ injection was obtained from Otsuka Pharmaceutical Co., Ltd. (Meylon 84, Tokyo, Japan).

Doxorubicin-Heparin (Dox-Hep) Complex-Hep-Na solution $(50 \mathrm{mg} / 5 \mathrm{ml})$ was added to Dox- $\mathrm{HCl}$ solution $(50 \mathrm{mg} / 5 \mathrm{ml})$. After cooling, the precipitate was collected by centrifugation, washed several times with a small volume of cold distilled water, and dried in vacuo. To show that the precipitate is not the base of $\mathrm{DOX}, \mathrm{NaHCO}_{3}$-treated Dox $-\mathrm{HCl}$ was processed in the same manner without $\mathrm{Hep}-\mathrm{Na}$.

Particle Counts of Dox-Hep Complex and $\mathrm{NaHCO}_{3}$-Treated Dox- $\mathrm{HCl}-\mathrm{Dox}-\mathrm{HCl}(10 \mathrm{mg})$ was dissolved in saline solution and filtered through a $0.22 \mu \mathrm{m}$ Millipore filter. The filtrate was made up to $150 \mathrm{ml}$ with saline solution. Novo-heparin $(1 \mathrm{ml})$ was added to the solution with stirring. Five minutes later, the number of particles formed was measured on a HIAC PC-305 (HIAC/Royco Instrument Division, Pacific Scientific Co., Ltd., California, U.S.A.). Another $1 \mathrm{ml}$ of Novo-heparin was added and the number of particles was again measured. Separately, Dox- $\mathrm{HCl}$ solution was treated with $\mathrm{NaHCO}_{3}(8.4 \%$ solution) and the number of particles was similarly measured. Measurement was done four times with $10 \mathrm{ml}$ of sample solution in each case, and the last three measured values were used to calculate the mean value; the first measurement was discarded.

Energy Micro Analysis X-Ray (EMAX) (Na, Cl and S)- $\mathrm{Na}, \mathrm{Cl}$ and $\mathrm{S}$ in $\mathrm{Dox}-\mathrm{HCl}$, Dox- $\mathrm{Hep}$ and $\mathrm{NaHCO}_{3}$ treated Dox- $\mathrm{HCl}$ were determined by using a Hitachi S-50 scanning electron microscope (Hitachi Ltd., Tokyo, Japan) at $20 \mathrm{kV}$ with an EMAX-1770 energy dispersing X-ray analyzer (Horiba Seisakusho Co., Ltd., Tokyo, Japan) at $20 \mathrm{eV}$ for $600 \mathrm{~s}$. The sample was fixed on an aluminum stub $(1 \times 1 \mathrm{~cm})$ with double-side adhesive tape and coated with carbon at $150 \AA$ thickness in a Hitachi $5 \mathrm{~GB}$ high vacuum evaporator ( $30 \mathrm{~A}$ and $1 \times 10^{-6}$ Torr).

Infrared (IR) Spectra_- IR spectra were obtained on an IR-810 spectrometer (Japan Spectroscopic Co., Ltd., Tokyo, Japan).

Visible Spectra_- The visible spectra of solutions of test materials (Dox-HCl, Dox-Hep, $\mathrm{NaHCO}_{3}$-treated Dox- $\mathrm{HCl}$ ) and a mixture of dimethyl sulfoxide (DMSO) and water $(1: 1)$ were determined (Shimadzu UV-240, Shimadzu Co., Ltd., Kyoto, Japan). Dox- $\mathrm{HCl}$ solution was added to Hep-Na solution and the mixture was filtered through a Mol-cut II SJGC (molecular weight cut-off, 10000; Nihon Millipore Co., Ltd., Tokyo, Japan). Hep-Na of low molecular weight in the filtrate was identified by methylene blue metachromasis.

Differential Scanning Calorimetry (DSC)-Measurements were made under $40 \mathrm{ml} / \mathrm{min}$ of $\mathrm{N}_{2}$ (SSC/580-II, DSC-20, DS-50 Data Processor, Seiko Instruments \& Electronics Co., Ltd., Tokyo, Japan).

High Performance Liquid Chromatography (HPLC)—A Nucleosil 5 C18 $(5 \mu \mathrm{m})$ column, $4 \mathrm{~mm}$ i.d. $\times 25 \mathrm{~cm}$ (Nagel, W. Germany), was used. The column was eluted with $\mathrm{MeOH}-\mathrm{H}_{2} \mathrm{O}$-acetic acid $(40: 35: 5, \mathrm{v} / \mathrm{v} \%$ ) at the flow rate of $1 \mathrm{ml} / \mathrm{min}(\lambda=495 \mathrm{~nm}, \times 0.04$ a.u.f.s. $)$. A $10 \mu \mathrm{l}$ aliquot of a test material $\left(5 \mathrm{mg}\right.$ in $100 \mathrm{ml}$ of DMSO- $\left.\mathrm{H}_{2} \mathrm{O}, 1: 1\right)$ was injected. A Hitachi HPLC-633, a Hitachi wavelength-tunable effluent monitor (Hitachi Ltd., Tokyo, Japan) and a Shimadzu Chromatopac-CRIB (Shimadzu Co., Kyoto, Japan) were used.

\section{Results and Discussion}

\section{Particle Counts by HIAC}

When Novo-heparin solution was added to Dox- $\mathrm{HCl}$ solution, an increase in the number of 2 to $5 \mu \mathrm{m}$ particles was evident. Addition of $2 \mathrm{ml}$ of Novo-heparin solution increased the

TABle I. Particle Counts in Doxorubicin Solution Mixed with Novo-heparin or Sodium Bicarbonate Solution

\begin{tabular}{llrrrrr}
\hline \hline \multirow{2}{*}{ Admixture } & & \multicolumn{4}{c}{ Particle diameter $(\mu \mathrm{m})$} \\
& & $>2$ & $>5$ & $>10$ & $>20$ & $>30$ \\
\hline \multirow{2}{*}{ Novo-heparin } & Blank (Dox) & 184 & 37 & 16 & 5 & 0 \\
& 1 ml added & 79935 & 36125 & 2063 & 9 & 3 \\
& Another 1 ml added & 179835 & 34676 & 75 & 18 & 2 \\
$\mathrm{NaHCO}_{3}$ & Blank (Dox) & 211 & 45 & 7 & 0 & 0 \\
$(8.4 \%)$ & 1 ml added & 608 & 81 & 26 & 5 & 1 \\
& Another 1 ml added & 2251 & 172 & 30 & 5 & 3 \\
\hline
\end{tabular}




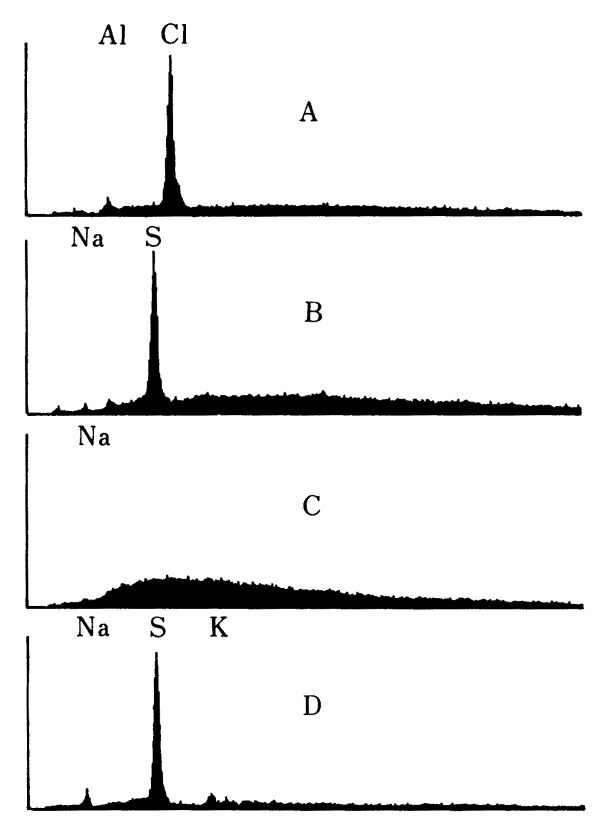

Fig. 1. EMAX of Dox-HCl (A), Dox-Hep Complex (B), $\mathrm{NaHCO}_{3}$-Treated Dox- $\mathrm{HCl}$ (C) and Hep-Na (D)

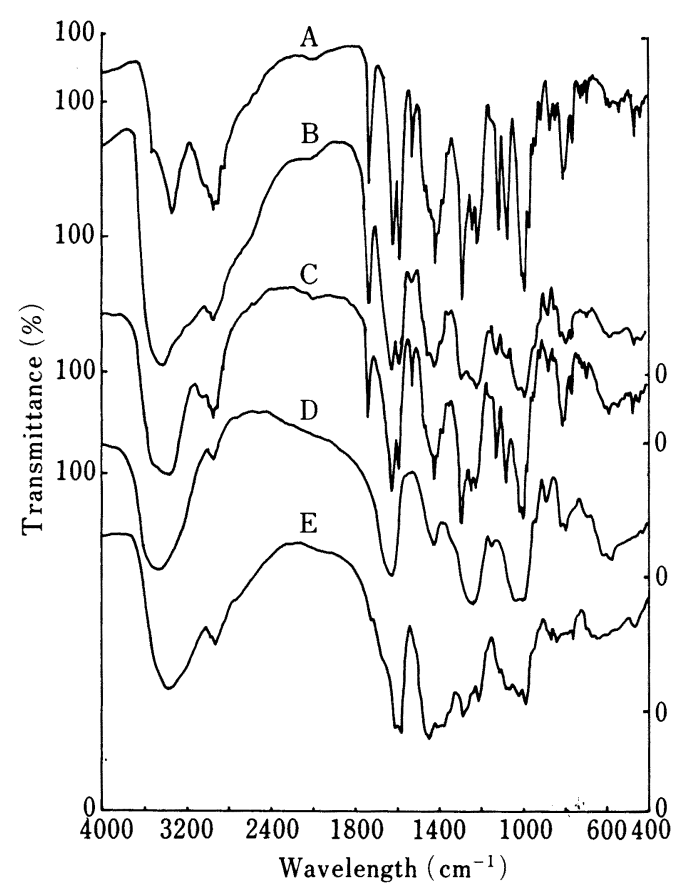

Fig. 2. IR Spectra of Dox-HCl, Hep-Na and Related Compounds

A, Dox-HCl; B, Dox-Hep complex; C, doxorubicin and heparin mixture; $\mathrm{D}$, Hep-Na; E, $\mathrm{NaHCO}_{3}$-treated Dox-HCl.

number to 1.5 to 2 times that when $1 \mathrm{ml}$ of the solution was added, while addition of $\mathrm{NaHCO}_{3}$ gave a particle number of about 1/90 of that determined with the Novo-heparin solution. Thus, the precipitation with heparin appears to be different from that with $\mathrm{NaHCO}_{3}$ (Table I).

\section{EMAX}

$\mathrm{X}$-Ray signals specific for $\mathrm{Cl}$ (as hydrochloride) and $\mathrm{Na}$ (as sodium salt) and for $\mathrm{S}$ (as $\mathrm{SO}_{3}^{2-}$ ) were observed for Dox- $\mathrm{HCl}$ and $\mathrm{Hep}-\mathrm{Na}$, respectively. No $\mathrm{Cl}$ was detected in Dox$\mathrm{Hep}$, but $\mathrm{S}$ and a trace amount of $\mathrm{Na}$ resulting from heparin were noted. A trace amount of sodium, probably from $\mathrm{NaHCO}_{3}$, was found in the $\mathrm{NaHCO}_{3}$-treated $\mathrm{Dox}-\mathrm{HCl}$, but $\mathrm{Cl}$ was not identified (Fig. 1). These results suggest the possibility of complex formation of Dox- $\mathrm{HCl}$ and Hep-Na.

\section{IR Spectra}

The IR spectrum of Dox-Hep differed from those of Dox-HCl, Hep-Na, the mixture of Dox- $\mathrm{HCl}$ and $\mathrm{Hep}-\mathrm{Na}$, and $\mathrm{NaHCO}_{3}$-treated Dox-HCl (Fig. 2).

Since IR $v_{\max }^{\mathrm{KBr}} \mathrm{cm}^{-1}: 1732(\mathrm{C}=\mathrm{O}$ of hydroxymethylketone $)$ and $1618(\mathrm{C}=\mathrm{O}$ of quinone $)$ still remain in Dox-Hep, the reaction may be considered to be a salt formation reaction. We designated Dox-Hep as a complex, as Govorovich and Bogomolova ${ }^{5)}$ and Bychkov ${ }^{6)}$ did in the case of binding of antibiotics to heparin.

\section{Visible Spectrum}

Dox-Hep in DMSO- $\mathrm{H}_{2} \mathrm{O}(1: 1)$ showed a similar spectrum to Dox- $\mathrm{HCl}$ (Fig. 3). When a Hep-Na solution was filtered through Mol-cut II and subjected to the methylene blue 


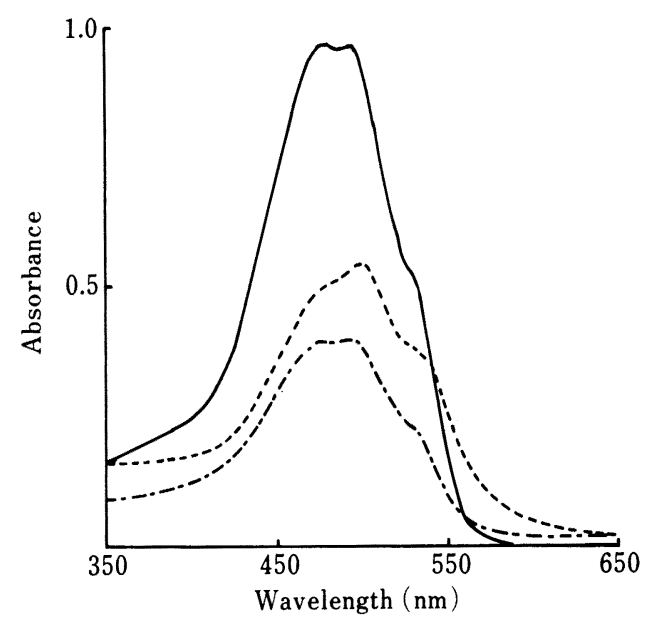

Fig. 3. Absorption Spectra of Dox-HCl, DoxHep Complex, and $\mathrm{NaHCO}_{3}$-Treated Dox$\mathrm{HCl}$

—, Dox-HCl $(0.498 \mathrm{mg} / 10 \mathrm{ml}) ;-\cdots,-\cdot \mathrm{NaHCO}_{3}$ treated Dox-HCl $(0.465 \mathrm{mg} / 10 \mathrm{ml}) ;-.-$ - Dox-Hep $^{-}$ complex $(0.422 \mathrm{mg} / 10 \mathrm{ml})$.

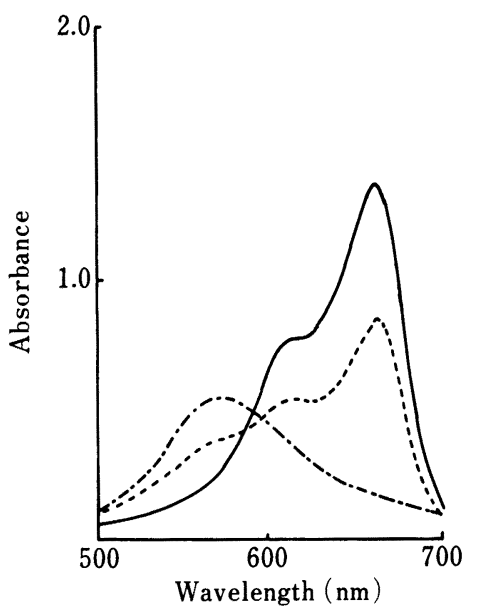

Fig. 4. Absorption Spectra of Dox- $\mathrm{HCl}$ and Hep-Na

After filtration through a Millipore Mol-cut II, methylene blue solution was added and the mixture was diluted with water.

- Dox- $\mathrm{HCl}(2.8 \mathrm{mg})$ and $\mathrm{Hep}-\mathrm{Na}(2.0 \mathrm{mg})$;

-.---, Dox- $\mathrm{HCl}(1.0 \mathrm{mg})$ and $\mathrm{Hep}-\mathrm{Na}(2.0 \mathrm{mg})$;

-.--, Hep-Na $(2.0 \mathrm{mg})$.

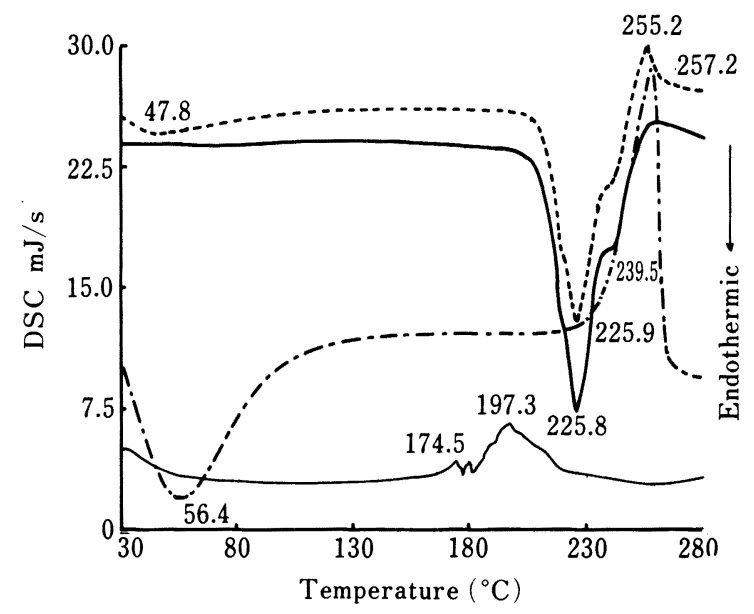

Fig. 5. DSC of Dox-HCl, Dox-Hep Complex and Related Compounds

- Dox-HCl; ------, Dox- $\mathrm{HCl}(85 \%)$ and Dox$\mathrm{Na}(15 \%)$ mixture; -...-. Hep-Na; _- DoxHep complex.

reaction, metachromasis developed (purple coloration). This is probably because Hep-Na of low molecular weight passed through the filter. When Dox- $\mathrm{HCl}$ was added to Hep- $\mathrm{Na}$ in an amount slightly larger than the complex-forming amount, metachromasis was not observed (Fig. 4). Presumably, Hep-Na remained as Dox-Hep complex on the filter and the filtrate was free from Hep-Na.

\section{DSC}

The mixture of Dox- $\mathrm{HCl}$ and $\mathrm{Hep}-\mathrm{Na}$ should give a thermogram pattern corresponding to the sum of those of Dox- $\mathrm{HCl}$ and $\mathrm{Hep}-\mathrm{Na}$ if there is no interaction. However, Dox-Hep showed a thermogram different from those of $\mathrm{Dox}-\mathrm{HCl}$ and $\mathrm{Hep}-\mathrm{Na}$, indicating that this product is a distinct complex (Fig. 5). 


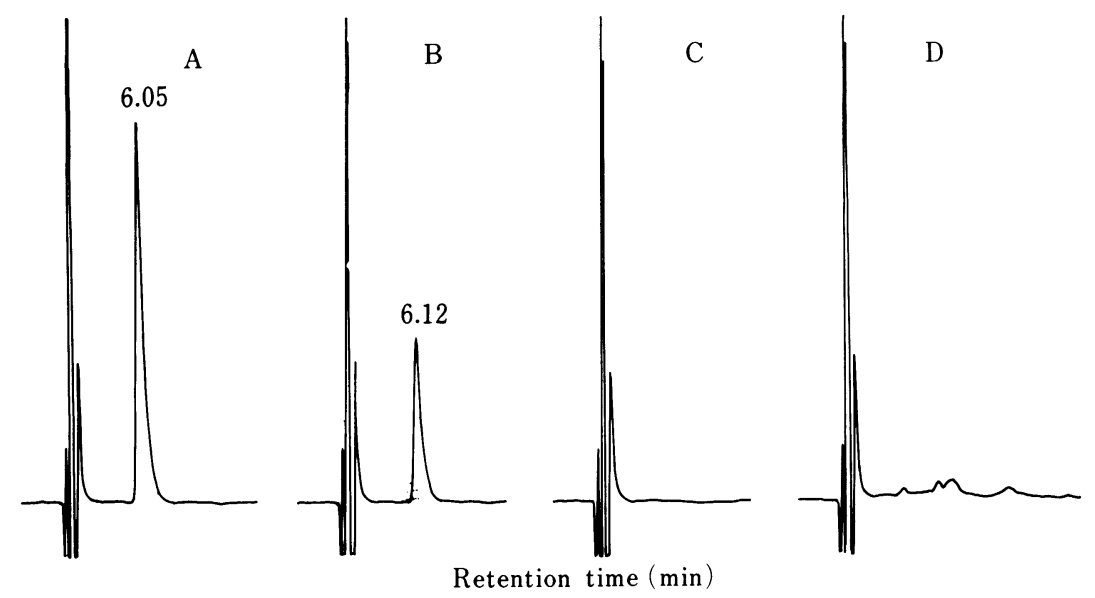

Fig. 6. HPLC of Dox-Hep, Dox Complex and Related Compounds

A, Dox- $\mathrm{HCl}(0.498 \mathrm{mg} / 10 \mathrm{ml}$, area 349407$)$; B, Dox-Hep complex $(0.422 \mathrm{mg} / 10 \mathrm{ml}$, area 150924); C, Hep- $\mathrm{Na}(0.407 \mathrm{mg} / 10 \mathrm{ml}) ; \mathrm{D}, \mathrm{NaHCO}_{3}$-treated Dox- $\mathrm{HCl}(0.465 \mathrm{mg} / 10 \mathrm{ml})$.

\section{HPLC}

Dox-Hep showed the same retention peak time as $\mathrm{Dox}-\mathrm{HCl}$ and its chromatogram differed from that of $\mathrm{NaHCO}_{3}$-treated Dox- $\mathrm{HCl}$ (Fig. 6). It appears that Dox- $\mathrm{HCl}$ is present as free doxrubicin in the DMSO- $\mathrm{H}_{2} \mathrm{O}$ solution. The amount of doxrubicin in Dox-Hep is $47.7 \%$ when calculated from the area ratio. If the molecular weight of $\mathrm{Hep}-\mathrm{Na}$ is assumed to be about 9800 , the amount of doxrubicin binding heparin can be calculated to be $47.8 \%$. This value agrees well with the HPLC result. Chemically, one molecule of Dox-Hep binds about 16 molecules of Dox. If the molecular weight of heparin is about 9800, that of Dox-Hep would be about 18000 , indicating the formation of a macromolecular complex.

Since heparin is a highly charged polysaccharide, binding and complexing with both large and small ions and molecules are possible. ${ }^{7)}$ Recent work on the incompatibility with morphine sulfate ${ }^{8)}$ and with gentamicin ${ }^{9)}$ indicated that heparin readily forms complexes with drugs containing an $\mathrm{NH}_{2}$ moiety.

In this experiment, we used commercial heparin sodium which might not be a pure product. Further the molecular weight distribution was not examined. It remains to be established whether low or high molecular weight heparin is preferable for drug-heparin complex formation in the biological context.

With regard to the effect of heparin, there are several reports on the inhibition of cell division, inhibition of protein synthesis, acceleration of tissue respiration and inhibition of tumor growth, although the mechanisms involved are not established. Recent reports by Folkman et al. ${ }^{10)}$ and Crum et al. ${ }^{11)}$ show that heparin or heparin fragment inhibited tumor growth in an animal study when heparin or heparin fragment and hydrocortisone were concomitantly administered. Thus, heparin may be very useful for the preparation of macromolecular anticancer agents with prolonged action and reduced side effects.

\section{References}

1) H. J. P. Ryser and W. Shen, Proc. Natl. Acad. Sci. U.S.A., 75, 3869 (1978).

2) H. Maeda, J. Takeshita and R. Kanemura, Int. J. Pept. Protein Res., 14, 81 (1979).

3) T. Iwa, M. Hirano, R. Wakasa, K. Sakai and M. Nakamura, Igaku No Ayumi, 121, 1136 (1982).

4) K. Kojima, M. Hashida, S. Muranishi and H. Sezaki, J. Pharm. Pharmacol., 32, 30 (1980).

5) E. A. Govorovich and N. S. Bogomolova, Antibiotiki, 14, 129 (1969). 
6) S. M. Bychkov, Vopr. Med. Khim., 12, 397 (1966).

7) J. Ehrlich and S. S. Stivala, J. Pharm. Sci., 62, 517 (1973).

8) D. E. Baker, C. S. Yost, V. E. Craig and R. K. Campbell, Am. J. Hosp. Pharm., 42, 1352 (1985).

9) M. I. Walter and W. H. Roberts, Ther. Drug Monit., 6, 199 (1984).

10) J. Folkman, R. Langer and R. J. Linhardt, Science, 221, 719 (1983).

11) R. Crum, S. Szabo and J. Folkman, Science, 230, 1375 (1985). 